
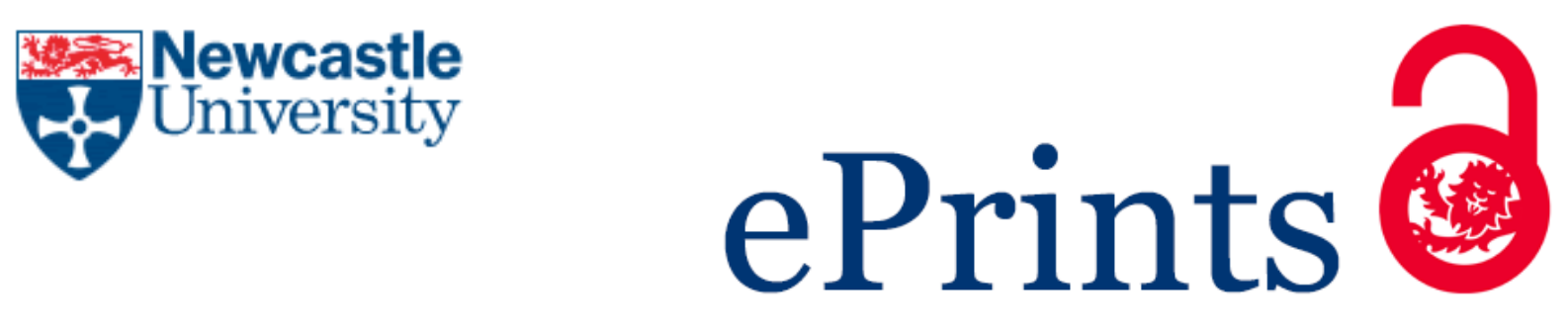

Romero-Sanchiz P, Nogueira-Arjona R, GodoyÁvila A,

Gavino-Lazaro A, Freeston $\mathrm{MH}$.

Assessing transdiagnostic intrusive thoughts: Factor structure, reliability and validity of the Cognitive Intrusions Questionnaire-Transdiagnostic version in a Spanish sample.

Personality and Individual Differences 2017, 114, 181-186.

Copyright:

(C) 2017. This manuscript version is made available under the CC-BY-NC-ND 4.0 license

DOI link to article:

https://doi.org/10.1016/j.paid.2017.04.008

Date deposited:

$13 / 04 / 2017$

Embargo release date:

12 April 2019

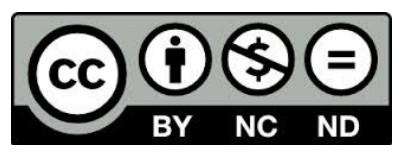

This work is licensed under a

Creative Commons Attribution-NonCommercial-NoDerivatives 4.0 International licence 
Article title: Assessing transdiagnostic intrusive thoughts: Factor structure, reliability and validity of the Cognitive Intrusions QuestionnaireTransdiagnostic version in a Spanish sample

Article reference: PAID8275

Journal title: Personality and Individual Differences

Corresponding author: Dr. Pablo Romero-Sanchiz

First author: Dr. Pablo Romero-Sanchiz

Final version published online: 12-Apr-2017

DOI information: 10.1016/j.paid.2017.04.008

Pablo Romero-Sanchiz, Raquel Nogueira-Arjona, Antonio Godoy-Ávila, Aurora Gavino-Lázaro, Mark H. Freeston, Assessing transdiagnostic intrusive thoughts: Factor structure, reliability and validity of the Cognitive Intrusions QuestionnaireTransdiagnostic version in a Spanish sample, Personality and Individual Differences, Volume 114, 1 August 2017, Pages 181-186, ISSN 0191-8869, http://doi.org/10.1016/j.paid.2017.04.008.

(http://www.sciencedirect.com/science/article/pii/S0191886917302532)

\section{Abstract}

Intrusive thoughts are typical symptoms of anxiety-related, mood and psychotic disorders. Freeston, Ladouceur, Thibodeau, and Gagnon (1991) developed the Cognitive Intrusions Questionnaire to address the features and processing of intrusive thoughts regardless of the theoretically related disorder. This study aims to assess the psychometric properties of a revised 79-item transdiagnostic version of the Cognitive Intrusions Questionnaire (CIQ-TV). A sample of 350 Spanish undergraduate students (mean age $21.68 ; 78.5 \%$ female) was used to assess its factor structure, internal consistency, test-retest reliability and criterion validity. Given the range of characteristics assesses questionnaire, the psychometric properties was studied on groups of ideas based on the components of a general appraisal model (intrusiveness, appraisals, emotions and strategies).

The CIQ-TV has a clear factor structure, internal consistency and test-retest reliability, except in the case of generalized anxiety disorder appraisals and thought-focused strategies. Criterion validity was good for obsessivecompulsive disorder and depression appraisals and appropriate for generalized anxiety disorder and social anxiety appraisals.

In summary, the results of this study showed that the CIQ-TV is a good measure for assessing intrusive thoughts and their associated processes.

Keywords: Intrusive thought; Intrusion; Obsession; Worry; Psychometric properties; Transdiagnostic 


\title{
Assessing transdiagnostic intrusive thoughts: Factor structure, reliability and validity of the Cognitive Intrusions Questionnaire-Transdiagnostic Version in a Spanish sample
}

\begin{abstract}
Intrusive thoughts are typical symptoms of anxiety-related, mood and psychotic disorders. Freeston, Ladouceur, Thibodeau, and Gagnon (1991) developed the Cognitive Intrusions Questionnaire to address the features and processing of intrusive thoughts regardless of the theoretically related disorder. This study aims to assess the psychometric properties of a revised 79-item transdiagnostic version of the Cognitive Intrusions Questionnaire (CIQ-TV). A sample of 350 Spanish undergraduate students (mean age $21.68 ; 78.5 \%$ female) was used to assess its factor structure, internal consistency, testretest reliability and criterion validity. Given the range of characteristics assesses questionnaire, the psychometric properties was studied on groups of ideas based on the components of a general appraisal model (intrusiveness, appraisals, emotions and strategies).

The CIQ-TV has a clear factor structure, internal consistency and test-retest reliability, except in the case of generalized anxiety disorder appraisals and thought-focused strategies. Criterion validity was good for obsessive-compulsive disorder and depression appraisals and appropriate for generalized anxiety disorder and social anxiety appraisals. In summary, the results of this study showed that the CIQ-TV is a good measure for assessing intrusive thoughts and their associated processes.
\end{abstract}

\section{Keywords}

Intrusive thought; intrusion; obsession; worry; psychometric properties; transdiagnostic; 


\section{Introduction}

\subsection{Background}

Different presentations of intrusive thoughts ${ }^{1}$ are typical symptoms of anxiety-related, mood or psychotic disorders, such as obsessions in obsessive-compulsive disorder (OCD), worries in generalized anxiety disorder (GAD), negative automatic thoughts and ruminations in depression, and/or delusions in psychotic disorders. The processing of intrusive thoughts is central to cognitive models of disorders such as OCD (e.g. Salkovskis, 1985), GAD (e.g. Dugas, Marchand, \& Ladouceur, 2005), illness anxiety/hypochondriasis (e.g. Warwick \& Salkovskis, 1990) and social phobia/anxiety (e.g. D. M. Clark \& McManus, 2002).

Various instruments have been developed since the 1980s that aim to assess the features of intrusive thoughts and their associated processes (D. A. Clark \& Purdon, 1995). Freeston et al. (1991) developed the Cognitive Intrusions Questionnaire (CIQ) to assess the features and processing of intrusive thoughts regardless of the theoretically related disorder ${ }^{2}$. In a series of articles, these authors used the CIQ to compare item-byitem features of obsession-like thoughts, worries and health concerns in non-clinical samples (Freeston et al., 1994, 1991; Freeston, Ladouceur, Thibodeau, \& Gagnon, 1992; Freeston \& Ladouceur, 1993).

This version of the CIQ was extended by the Laval research group to more thoroughly compare the same thought types (Langlois, Freeston, \& Ladouceur, 2000a, 2000b; Langlois, Ladouceur, Gosselin, \& Freeston, 2004). Furthermore, other researchers have extended this questionnaire by adding items related to depressive ruminations (Watkins, Moulds, \& Mackintosh, 2005), and it was also used to compare depressive and obsessive thoughts in clinical samples (Wahl et al., 2011). 
Although the CIQ has been used in a number of studies, its psychometric properties have never been assessed for a number of reasons. The first is that there are several versions of the questionnaire, each developed for different purposes and each requiring a separate validation and so impractical. A second reason might be related to the distinctive features of the CIQ. Typically, factor structure, reliability, and validity are assessed by considering the instrument as a whole. Given that the original purpose of this instrument is to assess different item-by-item features and processes of a range of thoughts, this approach is probably not realistic. We argue that it is not theoretically coherent to expect internal consistency from a group of variables that measure different constructs (e.g., obsessive appraisals, emotions provoked by worries, or different strategies). In this context, we posit that a different approach should be used to validate this instrument.

\subsection{Objectives and challenges}

Therefore, the main objective of this research is to establish the psychometric properties of a transdiagnostic version of the CIQ (CIQ-TV) while overcoming the three main challenges, which are as follows: a) the multiple versions, b) the complexity of the underlying multicomponent model, and c) the heterogeneity and variety of the items measuring both diagnosis specific and transdiagnostic components.

To overcome the first challenge, the CIQ-TV will be extended to enable assessment of the characteristics and processes associated with a wide variety of intrusive thoughts associated with a range of different disorders. 
To overcome the second and third challenges, an approach consistent with the objectives and features of the CIQ-TV will be developed that estimates structure, reliability and validity. Instead of using all the items as a whole, the items will be grouped based on theoretical criteria. The authors of the questionnaire organized the items into categories labeled intrusiveness, appraisals, emotions, and strategies. These categories can be interpreted as components of a model that encompasses the different ways in which intrusive thoughts are processed. In this model (see Fig. 1), the presence of a thought with intrusive characteristics (i.e., disturbance provoked by the thought) is appraised (i.e., responsibility) by the participant. The appraisals drive strategies through both direct paths (i.e. the appraisals indicate what needs to be done) and indirect paths where they can elicit different emotions (such as guilt) and thereby provide the signal or urgency to engage in the different strategies (such as distraction). This model will be referred to in the article as a general appraisals model. This model does not pretend to cover all psychopathology, but it does offer a transdiagnostic framework with central features or processes related to intrusive thoughts associated with various disorders.

In this manner, the factor structure is tested separately with a separate factor analysis for each component of the general appraisal model (intrusiveness, emotions, and strategies). The structure of appraisals will be tested in a slightly different manner. Given that large number of appraisal items in versions and because their content was heterogeneous, the appraisal-related items will be grouped based on the disorder to which they are theoretically most closely related. The grouping does not mean that the items are specifically related to a single disorder (i.e., the egodystonicity is relevant in OCD but also in GAD, or illness anxiety). Therefore, a single factor analysis will be performed for each group of disorder-related appraisals, provided that it is formed with a sufficient number of items. This strategy will only be used for appraisals rather than the other 
components of the model general features, emotions and strategies are not as characteristic of specific disorders. Because there are no previous data with this set of items, no explicit hypotheses will be formulated regarding the number of factors.

Internal consistency and test-retest reliability will be estimated by calculating one index for each component of the model, each group of the disorder-related appraisals, and each factor obtained in the analyses.

To assess the criterion validity, separate analyses will be conducted for disorderspecific appraisals and transdiagnostic components of the model (intrusiveness, emotions and strategies). In the first set of analyses, lenient and stringent tests will be performed. The lenient test determines whether the appraisals are related to the theoretically related psychopathology measure, whereas the stringent test determines whether this relationship remains after controlling for the appraisals considered characteristic of other disorders. For the transdiagnostic components, we will test whether each component makes a significant contribution to predicting the severity of the person's most severe symptoms (standardized score).

\section{Methods}

\subsection{Participants}

The sample consisted of 350 undergraduate students from three majors (Psychology, Social work and Journalism) of a Spanish University (mean age 21.68 [SD=4.05]; 78.5\% female; $89.5 \%$ single). The Psychology class completed the CIQ-TV one month after the first assessment to obtain test-retest reliability.

\subsection{Procedure}


The students completed the booklet containing the questionnaires as part of a practical class. All students signed an informed consent form prior to their participation in this research. The regional research board approved the study.

\subsection{Instruments}

2.3.2. Transdiagnostic version of the Cognitive Intrusions Questionnaire (CIQTV).

As explained in the introduction, the CIQ-TV was developed for this study. The development process can be found in Supplementary material.

\subsubsection{Obsessive Compulsive Inventory Revised (OCI-R; Foa et al., 2002).}

This questionnaire is formed by 18 items that were answered using a 5-point Likert scale. The Spanish version of this questionnaire has good psychometric properties $(\alpha=.88$; $\mathrm{r}=0.67)$ (Fullana et al., 2005).

\subsubsection{Worry and Anxiety Questionnaire (WAQ; Dugas, Freeston, Lachance,} Provencher \& Ladouceur, 1995).

Ten items answered on a 9-point Likert scale corresponding to the diagnostic criteria for GAD were used in this questionnaire. The Spanish version of the questionnaire has very good psychometric properties $(\alpha=.91 ; \mathrm{r}=.80)$ (Ibáñez et al., 2000).

\subsubsection{Beck Depression Inventory-II (BDI-II; Beck, Steer, \& Brown, 1996).}

This inventory is formed by 21 multiple-choice items whose content assembles typical symptoms of depression answered in a 4-point Likert scale. The Spanish version 
of the BDI has high internal consistency in both clinical and non-clinical samples $(\alpha=.89)$ (Sanz, Perdigón, \& Vázquez, 2003).

\subsubsection{Beck Anxiety Inventory (BAI; Beck, Epstein, Brown, \& Steer, 1988).}

This questionnaire consists of 21 anxiety items that are answered using a 4-point Likert scale. The Spanish version of this questionnaire has excellent internal consistency ( $\alpha=$.93) (Magán, Sanz, \& García-Vera, 2008).

\subsubsection{Social Phobia and Anxiety Inventory (SPAI; Turner, Beidel, Dancu, \&} Stanley, 1989).

The SPAI consists of 45 items divided into two subscales of Social Phobia and Agoraphobia answered on a 7-point Likert scale. Only the first subscale was used in this study. The Spanish version of this inventory showed excellent psychometric properties for this subscale $(\alpha=.95 ; \mathrm{r}=.77)$ (García-López, Olivares, Hidalgo, Beidel, \& Turner, 2001).

\subsection{Data Analysis Plan}

Independent exploratory factor analyses (EFAs) were performed for the components of the general appraisal model (intrusiveness, emotions and strategies) and for each disorder-related group of appraisals (OCD GAD and Depression appraisals). There were not enough items related to social anxiety or delusions appraisals for an EFA (two and three, respectively). However, these items are considered in supplementary analyses as rationally derived subscales.

All EFAs were performed using the principal axis factoring extraction method, and the Kaiser-Meyer-Olkin (KMO) value should exceed .50. (Hutcheson \& Sofroniou, 1999). Bartlett's test of sphericity should be significant as a measure of sampling 
adequacy. Kaiser's criterion, the scree plot, and parallel analysis on the permutations of the raw data, as recommended by O'Connor (2000), were used to decide the number of factors to retain. In case of discrepancy, interpretability was crucial to make a decision. Finally, an item is considered to belong to a factor if the weight on that factor is at least .32 and .10 higher than its weight on any other factor (Tabachnick \& Fidell, 2007).

Internal consistency and test-retest reliability were calculated for each component of the model, each disorder-related group of appraisals, and each factor, using Cronbach's $\alpha$ and intraclass correlation coefficients (ICC), respectively. These indices were also calculated for the delusion and social anxiety appraisals. Cronbach's $\alpha$ coefficients lower than .50 are considered unacceptable (George \& Mallery, 2016). ICCs lower than .40 are considered poor (Cicchetti, 1994).

Finally, to test the criterion validity of the questionnaire, two groups of tests were performed. For the disorder-specific components, stringent and lenient tests for each type of appraisal were performed using regression analyses, with the appraisals predicting a measure of a theoretically related psychopathology. In the lenient test, only age and gender are entered in the first step. In the stringent test, the other appraisals are entered in the second step before the appraisal under consideration. For the transdiagnostic components, the components of the model (intrusiveness, emotions and strategies) were introduced as a set in three steps as independent variables, rotating their order to be first and last. Given that transdiagnostic components were tested, each measure of psychopathology was standardized and the maximum z-score across the five variables for each participant was taken as indicator of transdiagnostic severity.

//Please insert Table 1 here// 


\section{Results}

\subsection{Item analyses}

\subsubsection{Structure.}

The analyses showed that the correlation matrices for the different components were optimal for factor analyses, except for the GAD appraisals, which was adequate (See KMOs, Bartlett's tests and variance explained in Table 1). Item loadings are presented in Tables S1 to S3.

The EFA performed with the intrusiveness component presented a clear single-factor solution according to Kaiser's criteria, scree plot and parallel analyses. The EFA of the OCD appraisals component was performed retaining one factor. Parallel analysis did not clearly distinguish between one and two factors: at two factors the eigenvalue of the observed data (1.244) was almost identical to the eigenvalue of the random data at 95 th percentile (1.242). However, Kaiser's criterion and scree plot indicated a single factor solution, and this was more interpretable. The EFA of the GAD appraisals performed retaining two factors, according to the three criteria. Oblimin rotation was selected because it correlated factors were expected. The first factor was formed by items related to positive beliefs about worries abd was named "Beliefs About Worries"; tThe second factor was formed from items about other processes related to GAD and was thus named "Other GAD" appraisals and included uncertainty, the excessiveness of the thought and other positive beliefs about worries. The EFA of the Depression appraisals indicated a sound single solution according to the three criteria. For the emotion items the results of parallel analysis did not clearly distinguish between two and three factors. However, Kaiser's criterion and scree plot indicated a three-factor solution, which was more interpretable. The first factor, named "Complex Emotions" included shame, anger, 
helplessness, hopelessness and inferiority. Four items related to guilt formed a second factor, named "Guilt-related Emotions". Finally, items about sadness, anxiety and fear formed the factor named "Basic Emotions". Item nine (Helplessness), loaded significantly on two factors and was excluded.

Finally, all items about strategies were included in the EFA, except for the first ("I do nothing") because it was not considered a strategy and the last ("Others") because of varying content precluding interpretation. Two factors were retained and. Varimax rotation was used because two factors were not expected to correlate, given that previous research has demonstrated opposing strategies. The first factor was named "Thoughtelimination Strategies" and the second "Thought-focused Strategies". The item 70c, ("Tell somebody") did not meet the criteria and was excluded.

\subsubsection{Internal consistency and test-retest reliability.}

The components of the model presented good internal consistency (see Table 1 for all internal consistency and test-retest reliability indices). With regard to disorder-related appraisals, the OCD appraisals presented good internal consistency. However, the first GAD appraisal factor, Beliefs About Worries, showed questionable internal consistency $(\alpha<70)$, while the second, Other GAD, presented low internal consistency $(\alpha<.50)$. The Depression appraisals showed an acceptable internal consistency index. All three emotions factors presented good internal consistency indices. The first strategy factor, (Thought-elimination Strategies) showed good internal consistency, but the second (Thought-focused Strategies) was questionable index $(\alpha<.70)$. The social anxiety and delusions appraisals presented questionable internal consistency indices $(\alpha<.70)$. 
For test-retest reliability, the ICCs varied from fair to good. Test-retest reliability for the intrusiveness and OCD appraisals factors was good, but the indices for GAD appraisal factors and Depression were only fair. The test-retest indices for the emotion factors varied from fair to good. Finally, ICCs for both strategy factors were fair. Social anxiety and delusions appraisals presented good and fair indices, respectively.

//Please insert Table 2 here//

\subsection{Criterion Validity}

With respect to disorder-specific analyses, as explained in the data analysis strategy section, lenient and stringent tests were performed for each appraisal type. The results yielded statistically significant relationships between appraisals and symptoms in both the lenient and stringent tests for OCD and depression. However, only the lenient tests yielded statistically significant relationships between the appraisals and GAD and social anxiety symptoms (Table 2).

For the analyses of the transdiagnostic components, the model was statistically significant model and explained $37.9 \%$ of the variance in transdiagnostic severity. All three sets made a statistically significant contribution regardless the order they were introduced; the size of each contribution varied by the order (Table 3).

//Please insert Table 3 here// 


\section{Discussion}

The objective of this study was to establish the psychometric properties of the CIQTV that assesses a generic appraisal model of cognitive intrusions in a transdiagnostic context. Intrusiveness, OCD appraisals, and Depression appraisals presented single-factor structures, GAD appraisals and strategies, two factors and emotions three factors.

All components of the general appraisals model (intrusiveness, appraisals, emotions and strategies) presented good internal consistency indices. Also, all factors obtained in the EFAs presented at least acceptable internal consistency, except for the Other GAD appraisals and Thought-focused Strategies factors. The low reliability for the Other GAD appraisals may result from the heterogeneity of the items, which are related to uncertainty or poor problem orientation (Dugas et al., 2005). With respect to the Thought-focused Strategies factor, a similar argument could be used, given that the strategies included punishment or preoccupation. Additionally, both factors consisted of only four items, which might also contribute to low internal consistency. In fact, the indices obtained in the components of the general appraisals model are higher, which is probably because they are formed by a larger number of items. However, as Streiner (2003) stated, high levels of internal consistency cannot be expected in factors that consist of theoretically heterogeneous items. Further, very high internal consistency would indicate overlap or redundancy. The test-retest reliability indices varied from fair to good for the components of the general appraisals model and the other factors. Taken together, the results for the CIQ-TV's reliability are satisfactory given the relatively short scales and varied content.

The results for the criterion validity of the appraisals component showed that OCD and depression met the stringent test, while GAD and social anxiety only met the lenient test, perhaps not unexpectedly, given the low reliability. However, taken together, the 
results support the criterion validity of the questionnaire. Finally, the results of the criterion validity of the transdiagnostic component showed that intrusiveness, emotions and strategies each contribute significantly to the variance of the most severe symptom. Taken together, these results indicate that the CIQ-TV has a good criterion validity, from both disorder-specific and transdiagnostic perspectives.

This study thus showed that the CIQ-TV is a reliable and valid measure for the processes associated with a variety of intrusive thoughts. The perspective adopted by the CIQ-TV would be useful for both clinical and research purposes, given that it captures economically a number of clinically-relevant phenomena, from an across diagnosis or transdiagnostic framework. Previous studies used the CIQ to compare different intrusive thoughts on an item-by-item basis. Although this approach was appropriate to the questions examined, the results of this study indicate that the variables evaluated by this measure also fit a general theoretical model. Furthermore, the items initially created for individual use also present at least acceptable reliability and validity when grouped as components of a model, thus strengthening the utility of the questionnaire.

As discussed briefly in the introduction, the main limitation of this instrument is that there are a small number of items for each construct, which may not fully capture each construct. However, this limitation results from a decision driven by practicality. In fact, one of the purposes of this study is to determine whether a questionnaire consisting of heterogeneous items contains reliable and valid groupings of the items as components of a theoretical model. The reliability of most scales was reasonable, especially given scale length. Another potential limitation is that the items were written in a neutral manner so they could be used with samples with different characteristics or disorders, but might have led to the misinterpretation of some items. For instance, there is only one item about uncertainty in order to assess related concepts such as intolerance of uncertainty (GAD), 
tolerance of uncertainty (OCD) or illness uncertainty (illness anxiety). However, the questionnaire had from good to acceptable criterion validity. Another limitation is the use of a non-clinical sample for the validation. However, numerous studies showed that intrusive thoughts are present in non-clinical samples (e.g. Rachman, 1978; Turner, Beidel, \& Stanley, 1992) as well as the relevance of analogue studies in the study of obsessions (Abramowitz et al., 2014). Another limitation is that test-retest reliability was calculated only for Psychology undergraduates for accessibility reasons. To the extent that this subsample is less representative of the entire sample is a limitation and less generalizable, but there is no reason to expect that the estimate would be particularly biased in either direction. Additionally, the age and gender of the sample can limit the generalization of the results. It would be interesting to replicate these results in a more heterogeneous sample.

Given that this questionnaire has been tailored to evaluate various forms of intrusive thoughts, the next step should be to apply it in different clinical samples and to evaluate the similarities and differences found. To the best of our knowledge, only one study (Wahl et al., 2011) has used the CIQ in clinical samples. Our research group is currently using this questionnaire on three clinical samples. Additionally, it would be necessary to translate this version of the questionnaire into other languages.

The main objective of this study was to establish the psychometric properties of the CIQ-TV. Despite its clinical utility and although it has been used in a number of studies, its psychometric properties have not been formally assessed until now, in part due to the flexible features of this questionnaire as a research tool. It was designed to assess a large number of heterogeneous variables to operationalize components of a model in various disorders rather than to provide a standardized assessment tool of single dimension or a few closely related dimensions. Despite the different intention of this measure, the results 
showed that the various components assessed by this questionnaire have adequate psychometric properties and that it is appropriate for assessing the features of intrusive thoughts and their processing across a range of disorders. As such, it helps span both disorder-specific and transdiagnostic approaches to the assessment of intrusive thoughts, an important feature of several important mental health problems. 


\section{References}

Abramowitz, J. S., Fabricant, L. E., Taylor, S., Deacon, B. J., McKay, D., \& Storch, E. A. (2014). The relevance of analogue studies for understanding obsessions and compulsions. Clinical Psychology Review. http://doi.org/10.1016/j.cpr.2014.01.004

Beck, A. T., Epstein, N., Brown, G., \& Steer, R. A. (1988). An inventory for measuring clinical anxiety: Psychometric properties. Journal of Consulting and Clinical Psychology, 56(6), 893-897. http://doi.org/10.1037/0022-006X.56.6.893

Beck, A. T., Steer, R. A., \& Brown, G. (1996). Beck Depression Inventory-II. San Antonio.

Cicchetti, D. V. (1994). Guidelines, criteria, and rules of thumb for evaluating normed and standardized assessment instruments in psychology. Psychological Assessment, 6(4), 284-290. http://doi.org/10.1037/1040-3590.6.4.284

Clark, D. A., \& Purdon, C. L. (1995). The assessment of unwanted intrusive thoughts: A review and critique of the literature. Behaviour Research and Therapy, 33(8), 967976. http://doi.org/10.1016/0005-7967(95)00030-2

Clark, D. M., \& McManus, F. (2002). Information processing in social phobia. Biological Psychiatry, 51(1), 92-100. http://doi.org/10.1016/S0006-3223(01)01296-3

Dugas, M. J., Marchand, A., \& Ladouceur, R. (2005). Further validation of a cognitivebehavioral model of generalized anxiety disorder: diagnostic and symptom specificity. Journal of Anxiety Disorders, 19(3), 329-43. http://doi.org/10.1016/j.janxdis.2004.02.002

Foa, E. B., Huppert, J. D., Leiberg, S., Langner, R., Kichic, R., Hajcak, G., \& Salkovskis, 
P. M. (2002). The Obsessive-Complusive Inventory: Development and validation of a short version. Psychological Assessment, 14(4), 485-495. http://doi.org/10.1037//1040-3590.14.4.485

Freeston, M. H., Gagnon, F., Ladouceur, R., Thibodeau, N., Letarte, H., \& Rhéaume, J. (1994). Health-related intrusive thoughts. Journal of Psychosomatic Research, 38(3), 203-215. http://doi.org/10.1016/0022-3999(94)90116-3

Freeston, M. H., \& Ladouceur, R. (1993). Appraisal of cognitive intrusions and response style: Replication and extension. Behaviour Research and Therapy, 31(2), 185-191. http://doi.org/10.1016/0005-7967(93)90070-B

Freeston, M. H., Ladouceur, R., Thibodeau, N., \& Gagnon, F. (1991). Cognitive intrusions in a non-clinical population. I. Response style, subjective experience, and appraisal. Behaviour Research and Therapy, 29(6), 585-597. http://doi.org/10.1016/0005-7967(91)90008-Q

Freeston, M. H., Ladouceur, R., Thibodeau, N., \& Gagnon, F. (1992). Cognitive intrusions in a non-clinical population. II. Associations with depressive, anxious, and compulsive symptoms. Behaviour Research and Therapy, 30(3), 263-271. http://doi.org/10.1016/0005-7967(92)90072-O

Fullana, M. a, Tortella-Feliu, M., Caseras, X., Andión, O., Torrubia, R., \& Mataix-Cols, D. (2005). Psychometric properties of the Spanish version of the ObsessiveCompulsive Inventory--revised in a non-clinical sample. Journal of Anxiety Disorders, 19(8), 893-903. http://doi.org/10.1016/j.janxdis.2004.10.004

García-López, L. J., Olivares, J., Hidalgo, M. D., Beidel, D. C., \& Turner, S. M. (2001). Psychometric Properties of the Social Phobia and Anxiety Inventory, the Social 
Anxiety Scale for Adolescents, the Fear of Negative Evaluation Scale, and the Social Avoidance and Distress Scale in an Adolescent Spanish-Speaking Sample. Journal of Psychopathology and Behavioral Assessment, 23(1), 51-59. http://doi.org/10.1023/A:1011043607878

George, D., \& Mallery, P. (2016). IBM SPSS Statistics 23 Step by Step: A Simple Guide and Reference. London: Routledge. http://doi.org/10.1177/1073191112446654

Hutcheson, G., \& Sofroniou, N. (1999). The multivariate social scientist. http://doi.org/10.4135/9780857028075

Langlois, F., Freeston, M. H., \& Ladouceur, R. (2000a). Differences and similarities between obsessive intrusive thoughts and worry in a non-clinical population: study 1. Behaviour Research and Therapy, 38(2), 157-173. http://doi.org/10.1016/S00057967(99)00027-3

Langlois, F., Freeston, M. H., \& Ladouceur, R. (2000b). Differences and similarities between obsessive intrusive thoughts and worry in a non-clinical population: study 2. Behaviour Research and Therapy, 38(2), 175-189. http://doi.org/10.1016/S00057967(99)00028-5

Langlois, F., Ladouceur, R., Gosselin, P., \& Freeston, M. H. (2004). Characteristics of illness intrusions in a non-clinical sample. Behaviour Research and Therapy, 42(6), 683-96. http://doi.org/10.1016/S0005-7967(03)00191-8

Magán, I., Sanz, J., \& García-Vera, M. P. (2008). Psychometric properties of a Spanish version of the Beck Anxiety Inventory (BAI) in general population. The Spanish Journal of Psychology, 11(2), 626-40.

O'connor, B. P. (2000). SPSS and SAS programs for determining the number of 
components using parallel analysis and Velicer's MAP test. Behavior Research Methods, Instruments, \& Computers, 32(3), 396-402. http://doi.org/10.3758/BF03200807

Rachman, S. (1978). Abnormal and normal obsessions. Behaviour Research and Therapy, 16(4), 233-248. http://doi.org/10.1016/0005-7967(78)90022-0

Salkovskis, P. M. (1985). Obsessional-compulsive problems: A cognitive-behavioural analysis. Behaviour Research and Therapy, 23(5), 571-583. http://doi.org/10.1016/0005-7967(85)90105-6

Sanz, J., Perdigón, A. L., \& Vázquez, C. (2003). Adaptación española del Inventario para la Depresión de Beck-II (BDI-II): 2. Propiedades psicométricas en población general. Clinica Y Salud, 14(3), 249-280.

Streiner, D. L. (2003). Starting at the beginning: an introduction to coefficient alpha and internal consistency. Journal of Personality Assessment, 80(1), 99-103. http://doi.org/10.1207/S15327752JPA8001_18

Tabachnick, B. G., \& Fidell, L. S. (2007). Using multivariate statistics. Boston: Pearson/Allyn \& Bacon.

Turner, S. M., Beidel, D. C., Dancu, C. V., \& Stanley, M. a. (1989). An empirically derived inventory to measure social fears and anxiety: The Social Phobia and Anxiety Inventory. Psychological Assessment: A Journal of Consulting and Clinical Psychology, 1(1), 35-40. http://doi.org/10.1037/1040-3590.1.1.35

Turner, S. M., Beidel, D. C., \& Stanley, M. A. (1992). Are obsessional thoughts and worry different cognitive phenomena? Clinical Psychology Review, 12(2), 257-270. http://doi.org/10.1016/0272-7358(92)90117-Q 
Wahl, K., Schönfeld, S., Hissbach, J., Küsel, S., Zurowski, B., Moritz, S., ... Kordon, A. (2011). Differences and similarities between obsessive and ruminative thoughts in obsessive-compulsive and depressed patients: A comparative study. Journal of Behavior Therapy and Experimental Psychiatry, 42(4), 454-461. http://doi.org/10.1016/j.jbtep.2011.03.002

Warwick, H. M. C., \& Salkovskis, P. M. (1990). Hypochondriasis. Behaviour Research and Therapy, 28(2), 105-117. http://doi.org/10.1016/0005-7967(90)90023-C

Watkins, E., Moulds, M., \& Mackintosh, B. (2005). Comparisons between rumination and worry in a non-clinical population. Behaviour Research and Therapy, 43(12), 1577-85. http://doi.org/10.1016/j.brat.2004.11.008 


\section{Footnotes}

${ }^{1}$ A broad definition of intrusive thought is used in this paper: "significant thought, images, or impulses that appear in consciousness and that are outside the direct control of the person".

${ }^{2}$ See Supplementary materials for a brief description of this and further versions of the CIQ. 
Fig. 1. General appraisal model.

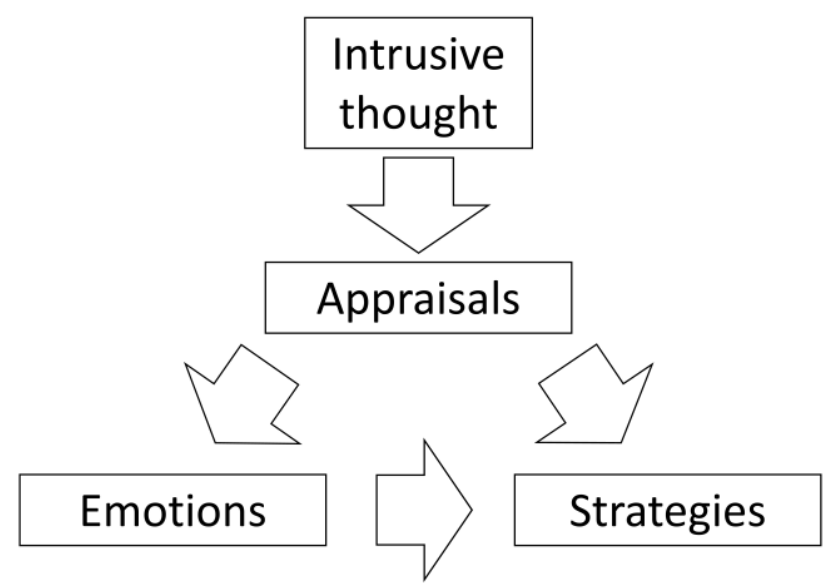


Table 1. Items grouping and reliability indices.

\begin{tabular}{|c|c|c|c|c|c|}
\hline \multirow[b]{2}{*}{ Components } & \multirow[b]{2}{*}{ Factors } & \multirow{2}{*}{$\begin{array}{l}\text { Internal } \\
\text { Consistency }\end{array}$} & \multicolumn{3}{|c|}{ EFAs } \\
\hline & & & retest $^{\mathrm{a}} \quad \mathrm{KMO}$ & $\begin{array}{l}\text { Bartlett's } \\
\text { test }\left(\chi^{2}\right)\end{array}$ & $\begin{array}{l}\% \text { of } \\
\text { variance }\end{array}$ \\
\hline Intrusiveness & & .74 & .835 & $1156.94 *$ & 45.13 \\
\hline $\begin{array}{l}\text { Appraisals } \\
\text { (total) }\end{array}$ & & .89 & .59 & & \\
\hline \multirow{7}{*}{ Appraisals } & OCD & .80 & .785 & $982.31 *$ & 33.32 \\
\hline & GAD (total) & .60 & .51 & & \\
\hline & Beliefs About Worries & .66 & .691 & $271.74 *$ & 61.79 \\
\hline & Other GAD & .47 & .41 & & \\
\hline & Depression & .74 & .739 & $500.17 *$ & 5.25 \\
\hline & Social Anxiety & .60 & .65 & & \\
\hline & Delusions & .69 & .53 & & \\
\hline $\begin{array}{l}\text { Emotions } \\
\text { (total) }\end{array}$ & & .87 & .58 & $2355.47 *$ & 59.72 \\
\hline \multirow{3}{*}{ Emotions } & Complex Emotions & .84 & 0 & & \\
\hline & Guilt & .79 & & & \\
\hline & Basic Emotions & .80 & & & \\
\hline $\begin{array}{l}\text { Strategies } \\
\text { (total) }\end{array}$ & & .80 & .820 & $982.31 *$ & 52.06 \\
\hline \multirow{2}{*}{ Strategies } & Thought-elimination & & & & \\
\hline & Thoughts-focused & & .55 & & \\
\hline \multicolumn{6}{|c|}{$\begin{array}{l}{ }^{*} \mathrm{p}<.001 ; \\
\mathrm{a}, \mathrm{N}=112 \text {, all ICC, } \mathrm{p}<.01 \text {. } \\
\text { Items: Intrusiveness }(1,2,33,34,37,39,54,60,64) \text {; OCD Appraisals }(25,26,27,28,32,36,40,41,61,63) \text {; Beliefs } \\
\text { About Worries Appraisals }(44,45,47) ; \text { Other GAD Appraisals }(35,46,48,53) ; \text { Depression Appraisals } \\
(8,11,13,15,16,17) ; \text { Social Anxiety appraisals }(22,23) \text {; Delusions appraisals }(42,51,52) \text {; Complex Emotions } \\
(6,7,9,12,14,18,20,21) \text {; Guilt }(5,29,30,31) \text {; Basic Emotions }(3,4,10) ; \text { Thought-elimination }(\mathrm{b}, \mathrm{d}, \mathrm{f}, \mathrm{g}, \mathrm{h}, \mathrm{i}) \text {; } \\
\text { Thoughts-focused }(c, \mathrm{e}, \mathrm{j}, \mathrm{k}) .\end{array}$} \\
\hline
\end{tabular}


Table 2. Criterion validity of appraisals.

\begin{tabular}{|c|c|c|c|c|c|c|c|}
\hline DV & Test & IV & $\Delta \mathrm{r}^{2}$ & $\mathrm{~F}$ & $\beta$ & $\mathrm{T}$ & $\mathrm{P}$ \\
\hline \multirow[t]{5}{*}{ OCI-R } & Lenient & OCD & .090 & 11,420 & .293 & 5.693 & $.000^{*}$ \\
\hline & Stringent & GAD & .097 & 7,336 & .112 & 1,786 & .075 \\
\hline & & DEP & & & .114 & 1,689 & .092 \\
\hline & & SP & & & -.008 & -.109 & .914 \\
\hline & & OCD & .013 & 7,066 & .171 & 2,294 & $.022 *$ \\
\hline \multirow[t]{5}{*}{ WAQ } & Lenient & GAD & .143 & 19,146 & .373 & 7,427 & $0.000 *$ \\
\hline & Stringent & OCD & .299 & & .181 & 2,752 & $.006^{*}$ \\
\hline & & DEP & & & .216 & 3,632 & $.000 *$ \\
\hline & & SP & & & .172 & 2,813 & $.005 *$ \\
\hline & & GAD & .008 & & .105 & 1,894 & .059 \\
\hline \multirow[t]{5}{*}{ BDI } & Lenient & DEP & .275 & 43,565 & .519 & 11,298 & $.000^{*}$ \\
\hline & Stringent & OCD & .225 & 19,875 & .093 & 1,410 & .159 \\
\hline & & GAD & & & .057 & 1,025 & .306 \\
\hline & & SP & & & .119 & 1,932 & .054 \\
\hline & & DEP & .079 & 24,873 & .372 & 6,236 & $.000 *$ \\
\hline \multirow[t]{5}{*}{ SPAI } & Lenient & SP & .152 & 2.592 & .323 & 6,503 & $.000 *$ \\
\hline & Stringent & OCD & .270 & 29,302 & .131 & 1,944 & .053 \\
\hline & & GAD & & & .356 & 5,820 & $.000 *$ \\
\hline & & DEP & & & .015 & .260 & .795 \\
\hline & & SP & .000 & 25,201 & .031 & .492 & .623 \\
\hline
\end{tabular}

${ }^{*} \mathrm{p}<.001 ; \mathrm{DV}$ : Dependent variable; IV: Independent variable from CIQ-TV; OCI-R: ObsessiveCompulsive Inventory-Revised; WAQ: Worry and Anxiety Questionnaire; BDI: Beck Depression Inventory; SPAI: Social Phobia and Anxiety Inventory; OCD: obsessive-compulsive disorder appraisals; GAD: generalized anxiety disorder appraisals; DEP: depression appraisals; SA: social anxiety appraisals; Lenient: age and gender included as covariables in the first step; Stringent: age and gender included as covariables in the first step and the remaining appraisals in the second. 
Table 3. Criterion validity of transdiagnostic components predicting most severe symptom score (Ztransformed) as a marker of transdiagnostic severity.

\begin{tabular}{llll}
\hline Equation & Step and component & $\Delta \mathrm{R}^{2}$ & $\mathrm{~F}$ \\
\hline \multirow{2}{*}{1} & 1. Intrusiveness & .307 & 50.923 \\
\cline { 2 - 4 } & 2. Emotions & .053 & 31.988 \\
\cline { 2 - 4 } & 3. Strategies & .019 & 25.907 \\
\hline 2 & 1. Emotions & .320 & 32.356 \\
\cline { 2 - 4 } & 2. Strategies & .040 & 27.435 \\
\cline { 2 - 4 } & 3. Intrusiveness & .018 & 25.907 \\
\hline \multirow{2}{*}{3} & 1. Strategies & .252 & 28.982 \\
\cline { 2 - 4 } & 2. Intrusiveness & .091 & 35.863 \\
\cline { 2 - 4 } & 3. Emotions & .035 & 25.907 \\
\hline
\end{tabular}

All $\Delta \mathrm{R}^{2} / \mathrm{F}$ 's significant at $\mathrm{p}<.001$ 